\title{
Introduction to the special issue: Media use and selectivity
}

\author{
HELENA BILANDZIC, FRIEDRICH KROTZ \\ and PATRICK RÖSSLER
}

An expanding media universe confronts readers, viewers, and users with an abundance of media content that, for the most part, will not be used by the audience, and will, in many cases, not even be considered for use. Selecting what to use and not to use is functional in avoiding information overload (Carlson, 2003) or 'technostress' (Rosen and Weil, 1997), but, at the same time, necessary to make use of the media environment. The selection of media initiates gratifications, serves particular functions, enables certain effects, all depending on the perspective. Media use and selectivity constitute a field of remarkable tradition in communication research. The question how individuals deal with media and why they use certain media content has been in the focus of communication research from the very beginning of empirical media research; since Lazarsfeld and his colleagues conducted their radio research projects (Lazarsfeld and Stanton, 1944), which included Herzog's (1944) widely cited study on daytime serial listeners. Thinking about media use reached a first prime with the emergence of Uses and Gratifications approaches; an abundance of studies about 'what people do with the media' have been published during the golden years of Uses and Gratifications in the 1970s and 1980s. Bryant and Miron (2004) identified Uses and Gratifications - along with Agenda Setting - as the approach most frequently used in three communication journals from 1956 through 2000.

Similar to the field of communication as a whole (Roe, 2003), research about media use has diversified considerably over the years. Different scholarly perspectives have given rise to separate research questions, methods, and terminology. Several factors were responsible for the enormous diversification of topics and perspectives. First, dissatisfaction with the theoretical foundations of existing media use concepts led to the development of new theories, often adaptations of theories from other fields of action theory to media action. Second, cultural and social dimensions obtained a new significance in scholarly thinking about media use. Third, new media and communication technologies such as mobile 
phones, internet use, and video games provide new research venues and demand different theoretical and empirical approaches.

This special issue brings together recent theoretical and empirical developments in media use and selectivity. The contributions of this special issue were originally presented at a conference of the Reception Studies Division of the German Communication Association (Deutsche Gesellschaft für Publizistik- und Kommunikationswissenschaft, DGPuK) held in Erfurt, Germany, in January 2006. Although the topics were diverse, the conference did not resemble a "frog convention" - a term used by Roe (2003: 56) who extended a metaphor used by Rosengren - with researchers croaking in individual ponds of their restricted research area instead of inhabiting a common pool and croaking a common language. The different foci on theory development, reasons for selection, and patterns of exposure created a picture of diversity, not incoherence; i. e., a mosaic that forms the knowledge we have about media use, yet one that does not and cannot claim completeness.

Three contributions to this special issue explicitly deal with theory development: Anne Bartsch, Roland Mangold, Peter Vorderer, and Reinhold Viehoff pursue the question why emotions instigated by the media become desirable for the audience. Integrating diverse theoretical fields in a framework, they argue for emotional gratifications on different levels of complexity. Oscar Peters, Matthias Rickes, Sven Jöckel, Christian von Criegern, and Alexander van Deursen deal with the explanation of the uses of 'new' media. They lay out a theoretical foundation for gratifications by applying Social Cognitive Theory, and then testing their model across different media and different countries in two studies. Christoph Klimmt, Andreas Nosper, Hannah Schmid, Tilo Hartmann, and Peter Vorderer address a media form that has increasingly attracted the attention of communication researchers in the past years, namely video games. This contribution focuses on how users continue to play and enjoy violent video games that disregard common moral standards. They develop a model of how users manage moral concerns about their brutal game actions, and explore the dimensions of this model in a qualitative study.

Two other contributions deal with the reasons for selective media use and employ online newspapers as stimuli, while focussing on different factors influencing selection and attention. Silvia Knobloch-Westerwick, Julia Brück, and Matthias R. Hastall investigate the reasons of genderspecific news selection. Their experiment analyzes the influence of gender-typical attitudes and motivations, such as self-esteem and achievement motivation, on the affinity of women and men towards social versus achievement topics. Hans-Jürgen Bucher and Peter Schumacher also look at the selection of news, but focus on the textual side. Using eye- 
tracking measures in three different studies, they reconstruct the selection and attention processes of news readers which result in patterns of selective use that systematically vary with types of content.

The final two contributions of the special issue take up issues of crossmedia use and repeated exposure. Uwe Hasebrink and Jutta Popp explore patterns of media use composed of television, radio, print news, and internet. Their secondary analysis of large datasets representative of the German population reveals a media-specific emergence of media repertoires and six different types of users. Jella Hoffmann investigates repeated exposure to movies. Her theoretical outline describes different processes of repeated viewing and related situational and personal factors influencing these processes.

Despite their different topics and perspectives, the approaches assembled in this special issue have common ground in that they consider the changing media environment in one way or another. They do not confine themselves to investigating traditional media, or to traditional ways of looking at media use. For example, the topics for research are extended beyond mass communication and include interactive media such as computer games. The theoretical horizon is extended by cross-fertilizations from neighbouring disciplines such as emotion or social psychology. The rise of digital media makes the audience's media environment more complex. As a consequence, it is getting easier to use a specific media product more often in different versions and to "play it again"; and even reading a newspaper at home may involve a print or several different online versions. All this changes 'what people do with the media', but it also raises new questions and calls for broader research efforts on media use and selectivity, marking a step into new relevant fields of research.

\section{References}

Bryant, J. and Miron, D. (2004). Theory and research in mass communication. Journal of Communication, 54(4), 662-704.

Carlson, C. N. (2003). Information overload, retrieval strategies and Internet user empowerment. In L. Haddon (Ed.), Proceedings. The good, the bad and the irrelevant (COST 269) (Vol. 1, pp. 169-173). Helsinki. Available at http://eprints.rclis.org/ archive/00002248/.

Herzog, H. (1944). What do we really know about daytime serial listeners? In P. F. Lazarsfeld and F. N. Stanton (Ed.), Radio Research, 1942-1943 (pp. 3-33). New York: Duell, Sloan and Pearce.

Lazarsfeld, P. F. and Stanton, F. N. (1944). Radio Research, 1942-1943. New York: Duell, Sloan and Pearce.

Roe, K. (2003). Communication Science: where have we been? Where are we now? Where are we going? Or: Media versus communication research? Communications: The European Journal of Communcation Research, 28, 53-59.

Rosen, L. and Weil, M. (1997). Technostress: coping with technology@Work, @ Home, (a) Play. New York: John Wiley. 